\title{
Study on hydro-environment stabilization of artificial lakes in karst areas
}

\author{
Y. Y. Wu ${ }^{1}$, P. P. Li ${ }^{1}$, Y. L. Zhu ${ }^{1}$, J. Z. Wang ${ }^{1}$ \& C. Q. Liu ${ }^{2}$ \\ ${ }^{1}$ Jiangsu Provincial Key Laboratory of Modern Agricultural Equipment \\ and Technology, Institute of Agricultural Engineering, \\ Jiangsu University, Zhenjiang, Jiangsu, People's Republic of China \\ ${ }^{2}$ State Key Laboratory of Environmental Geochemistry, \\ Institute of Geochemistry, Chinese Academy of Sciences, \\ Guiyang, People's Republic of China
}

\begin{abstract}
The hydro-environment in karst areas is changeable and fragile. Constructing artificial lakes can play a stabilizing role to the environment. Taking Lakes Hongfeng, Baihua and Aha in Guizhou in Southwest China as examples, this paper studies the lakes' stabilization of the hydro-environment of catchments. Through cluster analysis on hydro-chemical composition of karst areas, we discovered that the karst environment is greatly affected by the catchments environment, and chemical composition in water bodies also can sensitively mirror the input of pollutants. Hydro-chemical composition in artificial lakes is relatively stable, and they can buffer external input pressure from the environment. Through a correlation analysis on the concentration of phosphorus, sulphur, and nitrogen of the lake water body and the input quantity of pollutants from catchments, we can find out different proportion of pollutants to participate in chemical composition. Most of the pollutants joined the geochemistry cycle, which performs a self-purification function through sediment, biological metabolism, and diffusion. Moreover, through analysing the sediment and diffusion flux of phosphorus in Lake Baihua at different periods, we found that the ability to self-purify phosphorus in the lake was being weakened. These results offer a theoretical foundation for karst hydro-environmental improvement and protection.
\end{abstract}

Keywords: hydro-environment, karst, artificial lake. 


\section{Introduction}

Influenced by karstification, the water body in a karst region is not unified, and the water environment is fragile and unstable [1]. With the enhancement of industry and agricultural production activity, the mankind has caused the water environment to deteriorate through a large input of pollutants to the water body, especially such substances as nitrogen, phosphorus, sulphur, etc. [2, 3].

Guizhou is an area where the karst develops very well, and the water environment is extremely fragile too. Before 1960s, Guiyang, located in the centre of Guizhou Province, suffered a great shortage of water for industry, agriculture and domestic use. In addition, there was a great demand of water for electricity generation and travel, etc. Three artificial lakes - Lakes Hongfeng, Baihua and Aha -were constructed in succession in 1960s and 70s. These lakes play a role of regulating the worsening water environment day by day, and serving the social and economic development of neighboring areas. This paper attempts to discuss the stabilizing role of 3 artificial lakes in karst areas to hydroenvironment. The findings offer a theoretical foundation to improve and protect hydro-environmental of the karst areas.

\section{Description of the study site}

Lakes Hongfeng and Baihua are located in the middle of the plateau of Guizhou. They are the first grade reservoir of Maotiao River tributary and the second grade reservoir of Wujiang River tributary, which corrode the karst river valley physiognomy. The catchment area of Lake Hongfeng is $1596 \mathrm{~km}^{2}$, its water area $57.2 \mathrm{~km}^{2}$, and supply coefficient 49.6 , the maximum depth $45 \mathrm{~m}$, water residence time $0.325 \mathrm{a}$, capacity of reservoir 601 million $\mathrm{m}^{3}$. The catchment area of Lake Baihua is $1895 \mathrm{~km}^{2}$, its water area $14.5 \mathrm{~km}^{2}$, supply coefficient 182.2 , the maximum depth $45 \mathrm{~m}$, the average depth $12.6 \mathrm{~m}$, the water residence time $0.102 \mathrm{a}$, and the capacity of reservoir 182 million $\mathrm{m}^{3}$.

Lake Aha lies in the south of Guiyang city, and its catchment area is $190 \mathrm{~km}^{2}$, water area $3.4 \mathrm{~km}^{2}$, the average depth $13.2 \mathrm{~m}$, the water residence time $0.44 \mathrm{a}$, the capacity of reservoir 45 million $\mathrm{m}^{3}$. The lake region's physiognomy is mainly made up of the sandstone of the Permian and coal stratum and some carbonate rock of the Trias.

\section{The hydro-environment of karst areas}

\subsection{Cluster analysis of the water chemical composition in the karst areas}

Through a hierarchical cluster analysis of some chemical composition of water bodies in karst areas in Guizhou Province (Table 1, Fig.1), we found that 27 groups of data can be classified into 8 clusters. Lakes Hongfeng and Baihua can be classified into one cluster with consistency. Lake Aha can be classified into two clusters of Winter-Spring and Summer-Autumn. It shows that water chemical composition of Lake Aha is more changeable. The chemical 
composition of water body of Huangguoshu Falls, no matter in the place of Tianxingjiao, Shuiliandong or Lushuidong, can be classified into one. It also shows that water chemical composition is similar. Because of the relatively great area of water gathering of Lakes Hongfeng, Baihua and Huangguoshu Falls, their environment is very stable, and because of the small capacity of Lake Aha, the lake's environment is unstable, and it is relatively sensitive to the input substances from external environment.

\subsection{The mechanism of stabilizing the sulphate in lake water body}

Sulphate from outside was input into the artificial lakes. The concentration of sulphate in water body is steady in certain range. This is because lake sediments have redox of living organisms [4]. From the results of study on Lakes Aha and Baihua $[4,5]$ we infer that the concentration of sulphate has the tendency of reduction from water body surface to sediments interface, the concentration drops extremely rapidly from the interface to the sediments. Obviously, it is relevant to redox of living organisms in this layer.

\subsection{The mechanism of stabilizing the total nitrogen in lake water body}

Nitrogen from outside was input into the artificial lakes. The concentration of nitrogen in water body remains steady in certain range, and even drops. This is because lake sediments have deposition function on the nitrogen. From the results of study on Lakes Baihua and Hongfeng [6,7], we found that the average concentration of nitrogen in Lake Baihua was $4.20 \mathrm{mg} / \mathrm{L}$ in $1996,2.87 \mathrm{mg} / \mathrm{L}$ in 2001, that in Lake Hongfeng the average concentration $4.70 \mathrm{mg} / \mathrm{L}$ in 1996, 2.79 $\mathrm{mg} / \mathrm{L}$ in 2001 . The concentration of nitrogen tended to increase from water body surface to sediments interface, and the concentration decreases extremely rapidly from the interface to the sediments. It suggests an extremely great activity of redox of living organisms and nitrogen absorption in sediments. And exchangeable nitrogen content at sediments section in Lakes Baihua and Hongfeng is smaller than $5 \%$.

\subsection{The mechanism of stabilizing the phosphors in lake water body}

Phosphorus deposition is an important factor to stabilize phosphorus in lake water bodies except that a large amount of alga can uptake a large amount of phosphorus. Table 2 shows concentration of phosphorus in the water body and flux of phosphorus among sediments in Lake Baihua.

From Table 2, it can be seen that the P concentration of top layer sediments in 1998 was obviously greater than that in 1994, concentration of phosphorus in water body in 1998 was greater than that in1994. It is because phosphorus sediment flux was far greater than phosphorus diffusion flux, that in 1998 far greater than that in1994. It shows that the water body can stabilize the concentration of phosphorus. 
Table 1: Chemical composition of the water in karst areas in central Guizhou (mg/L).

\begin{tabular}{|c|c|c|c|c|c|c|c|c|c|}
\hline Water type, location and season & No. & $\mathrm{Cl}^{-}$ & $\mathrm{NO}_{3}^{-}$ & $\mathrm{SO}_{4}{ }^{2-}$ & $\mathrm{HCO}_{3}^{-}$ & K & $\mathrm{Na}$ & $\mathrm{Ca}$ & $\mathrm{Mg}$ \\
\hline SW,Baiyanjiao,Pingba,summer & 1 & 5.72 & 3.72 & 26.88 & 211.67 & 0.08 & 0.44 & 39.24 & 27.32 \\
\hline SW, Jiangsuotun,Anshun,autumn & 2 & 7.34 & 8.85 & 36.19 & 184.22 & 1.48 & 1.08 & 50.80 & 16.88 \\
\hline SW,Jiangsuotun,Anshun, summer & 3 & 9.76 & 3.36 & 38.98 & 324.76 & 0.98 & 2.53 & 69.32 & 33.42 \\
\hline DW, Liangsuotun,Anshun,autumn & 4 & 16.29 & 9.82 & 49.55 & 145.42 & 0.55 & 1.10 & 43.24 & 20.53 \\
\hline DW, Jiangsuotun,Anshun, summer & 5 & 5.72 & 10.80 & 44.74 & 130.91 & 0.04 & 0.83 & 39.24 & 15.19 \\
\hline SW, Fengjiazhai,Puding, summer & 6 & 6.53 & 5.92 & 38.98 & 239.18 & 0.08 & 0.30 & 57.80 & 24.92 \\
\hline SW, Wangjiazhai,Pingba, autumn & 7 & 6.53 & 7.50 & 31.78 & 268.22 & 0.23 & 0.41 & 66.48 & 23.50 \\
\hline SW, Liujiazhai,Pingba, autumn & 8 & 8.17 & 7.26 & 40.42 & 260.17 & 1.95 & 0.94 & 65.92 & 24.16 \\
\hline $\begin{array}{l}\text { RW, Tianxingjiao,Huangguoshu, } \\
\text { autumn }\end{array}$ & 9 & 1140 & 8.72 & 106.8 & 177.75 & 1.79 & 12.44 & 65.88 & 18.55 \\
\hline $\begin{array}{l}\text { RW, Tianxingjiao,Huangguoshu, } \\
\text { summer }\end{array}$ & 10 & 10.58 & 2.81 & 89.76 & 179.34 & 1.76 & 6.62 & 64.92 & 18.84 \\
\hline $\begin{array}{l}\text { RW, Shuiliandong,Huangguoshu, } \\
\text { autumn }\end{array}$ & 11 & 8.95 & 6.10 & 112.0 & 168.06 & 1.76 & 15.71 & 63.76 & 17.89 \\
\hline $\begin{array}{l}\text { RW, Shuiliandong,Huangguoshu, } \\
\text { summer }\end{array}$ & 12 & 8.95 & 2.07 & 92.16 & 158.36 & 1.83 & 8.12 & 57.80 & 18.23 \\
\hline $\begin{array}{l}\text { RW, Lushuidong,Huangguoshu, } \\
\text { autumn }\end{array}$ & 13 & 8.17 & 5.31 & 136.4 & 169.64 & 1.79 & 18.84 & 68.08 & 19.87 \\
\hline $\begin{array}{l}\text { RW, Lushuidong,Huangguoshu, } \\
\text { summer }\end{array}$ & 14 & 8.95 & 3.05 & 86.98 & 174.52 & 1.91 & 8.19 & 59.92 & 18.84 \\
\hline SW, Qingzhen, autumn & 15 & 6.53 & 7.50 & 15.36 & 180.99 & 1.44 & 0.46 & 42.16 & 15.90 \\
\hline LW, Lake Aha, spring & 16 & 9.50 & 0.98 & 270.4 & 270.41 & 4.09 & 4.83 & 137.8 & 15.67 \\
\hline LW, Lake Aha, summer & 17 & 8.59 & 1.29 & 180.2 & 190.29 & 4.73 & 3.78 & 108.2 & 14.02 \\
\hline LW, Lake Aha, autumn & 18 & 7.80 & 1.20 & 205.7 & 214.85 & 4.42 & 3.35 & 140.5 & 15.62 \\
\hline LW, Lake Aha, winter & 19 & 8.31 & 0.78 & 241.7 & 250.98 & 4.42 & 3.86 & 178.8 & 19.27 \\
\hline LW, Lake Hongfeng, spring & 20 & 5.60 & 0.98 & 74.98 & 81.56 & 3.42 & 2.96 & 73.79 & 10.95 \\
\hline LW, Lake Hongfeng, summer & 21 & 4.71 & 1.14 & 75.31 & 81.18 & 2.94 & 2.96 & 61.92 & 10.81 \\
\hline LW, Lake Hongfeng, autumn & 22 & 4.23 & 1.16 & 72.68 & 78.16 & 2.81 & 2.63 & 63.48 & 11.84 \\
\hline LW, Lake Hongfeng, winter & 23 & 5.31 & 1.34 & 70.36 & 77.28 & 2.97 & 2.72 & 58.63 & 11.62 \\
\hline LW, Lake Baihua, spring & 24 & 4.85 & 1.26 & 71.62 & 77.72 & 3.02 & 1.86 & 72.68 & 12.43 \\
\hline LW, Lake Baihua, summer & 25 & 5.40 & 1.40 & 72.24 & 79.69 & 3.27 & 1.89 & 53.64 & 9.95 \\
\hline LW, Lake Baihua, autumn & 26 & 4.36 & 1.01 & 54.24 & 59.89 & 2.88 & 1.54 & 50.01 & 9.50 \\
\hline LW, Lake Baihua, winter & 27 & 5.03 & 1.15 & 60.74 & 67.16 & 2.90 & 1.77 & 54.09 & 10.31 \\
\hline
\end{tabular}

SW: Spring Water; DW: Dropping Water; RW: River Water; LW: Lake Water.

From table 2, it can be seen that the phosphorus diffusion flux /the phosphorus sediment flux $(\mathrm{Fd} / \mathrm{Fs})$ is increased rapidly, the gradient of concentration of phosphorus reduced rapidly. It will certainly reduce the buffer capacity by changing phosphorus concentration of water body gradually. If $\mathrm{Fd} / \mathrm{Fs}$ was close to 1 , the water body would lose the ability to stabilize the hydroenvironment. 


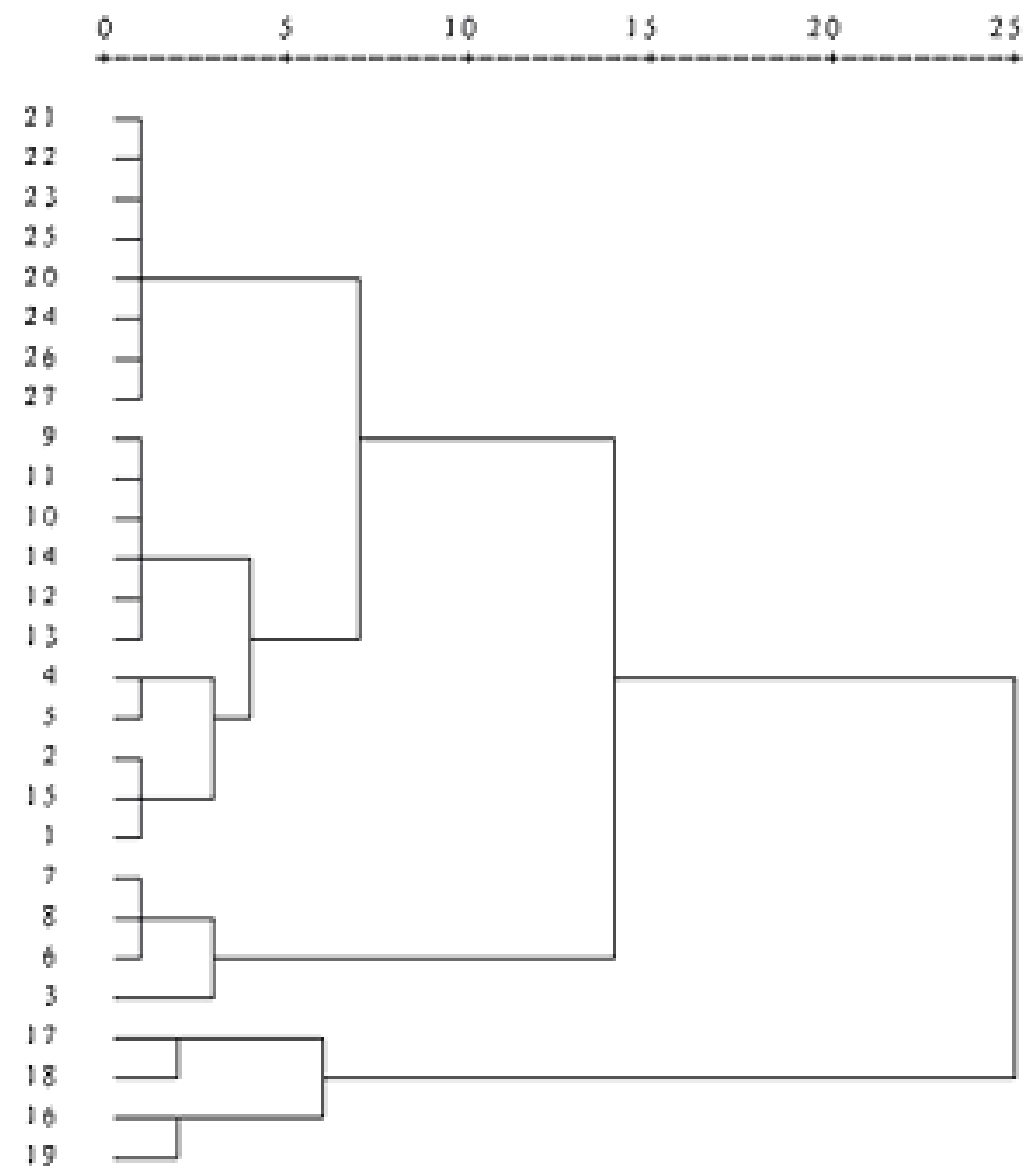

Figure 1: Map of hierarchical cluster analysis on some chemical composition of water bodies in karst areas in Guizhou Province.

\subsection{About purging silt}

The sediments contain a large number of pollutants, which are the endogenous pollutants in the lake. Purging silt can get rid of some endogenous pollutants, but destroy the stability of the ecosystem of the sediment interface, weaken the stability of lake water body. To maintaining the lake water body's ability to stabilize the water environment, it is significant to improve the purging silt methods, implement eco-dredging technology [8], and protect the ecosystem of the sediment interface. 
Table 2: Concentration of phosphorus in the water body and flux of phosphorus among sediments in Lake Baihua [9-11].

\begin{tabular}{lll}
\hline & \multicolumn{2}{c}{$\begin{array}{c}\text { Sediments gathered } \\
\text { time }\end{array}$} \\
\cline { 2 - 3 } mm/yyyy
\end{tabular}

\section{Conclusions}

The karst hydro-environment is changeable and fragile. Constructing artificial lakes can play a stabilizing role to hydro-environment. Most pollutants can join the element geochemistry cycle, which performs self-purification function such as deposition, biological metabolism, diffusion in water body, etc.. The stabilizing ability of the lake water body is related to the import of the external pollutants. With the pollution worsening, the stability is being weakened. Purging the silt of lake should be carried out under the premise of protection the water body ecosystem. These conclusions offer a theoretical foundation to the protection and improvement of hydro-environment of the karst areas.

\section{Acknowledgements}

The work is supported by Start Foundation of Senior Talents of Jiangsu University and the National "The tenth Five-Year Plan" great science and technology special (No. 2003AA601100-3).

\section{References}

[1] Bai, Z.G., Wu, F.C., Wan, X., Zou,S.Q. \& Wan,G.J., Mechanism of seasonal deterioration of water quality in lake Baihua,China. Chinese Journal of Geochemistry, 15(2), pp.185-188,1996.

[2] Zhao, J.F., Investigations on non-point source pollution lake Hongfeng catchment. Environmental protection science and technology, 17(1), pp.19, 1995.

[3] Liang, X.J., Zhang, M.S., Wang, A.M.\& Fu, W.J., Investigation on head waters, sources of pollutionmain nutrient elements and pollutants of Hongfeng and Baihua lake. Journal of Guizhou Normal University(Natural Science), 17(2), pp.37-39, 1999. 
[4] Wan, X., Wan, G.J., Huang, R.G. \& Pu,Y., Biogeochemical effect on postdepositional remobilisation of Fe-Mn in Lake Aha,Guizhou province. Journal of Lake Sciences, 9(2), pp.129-134 , 1997.

[5] Wu, F.C., Wan, G.J., Huang, R.G. \& Cai,Y.R., Environmental impact of sulphate concentration increasing of lakes. Acta Scientiae Circumstantiae, 18(1), pp.28-33, 1998.

[6] Xiao, H.Y. \& Liu,C.Q., The differentiated and analyse on endogenous nitrogen import and exterior nitrogen release in lakes. Science in China (Series D), 33(6), pp.576-582, 2003.

[7] Wang, Y.C., Wan, G.J., Yin, C.Q. \& Huang, R.G., Distribution of total, exchangeable and fixed nitrogen in the sediments of two lakes in Guizhou province. Journal of Lake Sciences, 14(4), pp.301-309, 2002.

[8] Liu, H.L., Jin,X.C. \& Jing,Y.F., Environmental dredging technology of lake sediment. Engineering science of China, 1(1), pp.81-84,1999.

[9] Wu, F.C., Bai, Z.G., Wan, G.J. \& Wan, X., Remobilization of P in the sediments of Lake Baihua, Guizhou. Advances in Environmental Science, 4(3), pp.58-61, 1996.

[10] Wang, Y.C., Wan, G.J., Wan, S.L.,Li, S.H. \& Huang, R.G., Forms of phosphorus in sediments of lake Baihua and Lake Hongfeng,Guizhou. Acta Mineralogica Sinica, 20(3), pp.273-278, 2000

[11] Wang, Y.C., Wan, G.J., Huang, R.G., Zou, S.Q. \& Chen, G.C., Geochemistry and environmental effect of modern sediments in Lake Baihua, Environmental science of Chongqing, 22(4), pp.39-41, 2000. 